\title{
Numerical Analysis of Thermal Convection in a CPU Chassis
}

\author{
M. Z. I. Bangalee ${ }^{1,2}$, Md. Mizanur Rahman ${ }^{1,2}$, M. Ferdows ${ }^{1,2}$, M. S. Islam³ \\ ${ }^{1}$ Department of Applied Mathematics, University of Dhaka, Dhaka, Bangladesh \\ ${ }^{2}$ Research Group of Fluid Flow Modeling and Simulation, Department Applied Mathematics, University of Dhaka, Dhaka, \\ Bangladesh \\ ${ }^{3}$ Department of Mathematics, University of Dhaka, Dhaka, Bangladesh \\ Email: ${ }^{\star}$ zavid@du.ac.bd
}

How to cite this paper: Bangalee, M.Z.I., Rahman, Md.M., Ferdows, M. and Islam, M.S. (2021) Numerical Analysis of Thermal Convection in a CPU Chassis. Open Journal of Modelling and Simulation, 9, 43-58. https://doi.org/10.4236/ojmsi.2020.91003

Received: September 17, 2020

Accepted: January 12, 2021

Published: January 15, 2021

\section{Copyright (c) 2021 by author(s) and} Scientific Research Publishing Inc. This work is licensed under the Creative Commons Attribution International License (CC BY 4.0).

http://creativecommons.org/licenses/by/4.0/

(cc) (i) Open Access

\begin{abstract}
Flow distribution and the effects of different boundary conditions are achieved for a steady-state conjugate (Conduction \& Convection) heat transfer process. A plate fin heat sink with horizontal fin orientation along with a computer chassis is numerically investigated and simulated using software ANSYS CFX. Fin orientation of a heat sink changes the direction of fluid flow inside the chassis. For predicting turbulence of the flow inside the domain, a two-equation based $k-\mathcal{E}$ turbulence model is chosen. The Reynolds number based on inflow velocity and geometry is found $4.2 \times 10^{3}$ that indicates that the flow is turbulent inside the chassis. To get proper thermal cooling, the optimum velocity ratio of inlet/outlet, dimension of inlet/outlet and different positions of outlet on the back sidewall of the chassis are predicted. Aspect velocity ratio between the inlet airflow and the outlet airflow has an effect on the steadiness of the flow. Mass flow rate depends on the dimension of the inlet/outlet. The horizontal fin orientation with 1:1.6 inlet-outlet airflow velocity ratio gives better thermal performance when outlet is located at the top corner of the chassis, near to the inner sidewall. Flow distribution and heat transfer characteristics are also analyzed to obtain the final model.
\end{abstract}

\section{Keywords}

Reynolds Number, Turbulence Model, Heat Sink, CPU Chassis, Conduction, Convection

\section{Introduction}

An Integrated Circuit (IC) is a small semiconductor chip usually made of silicon. 
It can contain thousands to millions of diodes, transistors, resistors and capacitors. These small electronics can perform calculations and store data using either digital or analog technology. When an IC is used to control the whole computer system is known as Central Processing Unit (CPU) or simply processor. It is the most interesting piece of hardware system and considered as the brain of a microcomputer. In modern microcomputers, the processor is square inch or so in size.

The CPU is responsible for processing most of the data within the computer system. That's why CPU generates a great deal of undesirable heat in modern computing system. When the data is processed, heat is generated. Once heat threshold is exceeded, CPU is placed at a risk of malfunction or permanent damage [1]. At the very beginning, processors were able to operate safely without heat removal system. The first Intel processors were already producing considerable amount of heat but low specification allowed operation without any heat removal mechanism [2]. At the present time, as the processor speed increased, these processors are going to generate a large amount of heat, for example, Intel core i7 7700k dissipate $91 \mathrm{~W}$ of heat within the area of $37.5 \mathrm{~mm} \times 37.5$ $\mathrm{mm}$ [3]. Therefore, a heat removal system with proper boundary conditions is obvious for these processors.

Many researchers have worked on air based heat sink where a cooling fan is necessary. This is very common approach for cooling personal computers. However, many liquids based heat sinks are also available. An isolated chip dissipating $100 \mathrm{w}$ could be cooled by forced-air convection [4]. Tuckerman and Pease [4] designated and tasted a very compact; water cooled integral heat sink for silicon integrated circuit. A $50 \mu \mathrm{m}$ wide and $300 \mu \mathrm{m}$ deep micro channel heat sink is capable of dissipating a power density of $790 \mathrm{~W} / \mathrm{cm}^{2}$ with a junction temperature of $71^{\circ} \mathrm{C}$. Heat sink combined with heat pipe and cooling fan were investigated at different times [5] [6] [7] [8] to improve thermal management of Laptop and personal computers. Heat sink together with cooling fan is also studied at different times to cool the heated component in computer chassis. Yuji et al. [9] studied fan heat sink cooling technology for laptop, desktop and several applications. Stafford et al. [10] investigate flat plate heat transfer with axial fan flows. Zheng [11] made a simulation for cooling fan.

Low power dissipating CPU can be cooled by natural convection without cooling fan. The driving force for natural convection is gravity. Mousavi et al. [12] investigate the natural convection and radiation heat transfer from vertical heat sinks with various configurations of fins to find the preferred design among the investigated cases and present the result in the form of streamline, velocity magnitudes, temperature contours, mean Nusselt numbers, average temperature of heat sinks and the radiation to total heat transfer ratio. As modern CPU can be placed at a risk of malfunction for natural convection. Shi et al. [13] present a method of designing an air heat sink with force convection by topological optimization. This method requires lower pumping power when compared others. They evaluated both pressure drop and heat transfer performances. The opti- 
mized structure is manufactured and experimentally validated. In forced convection, mass flow rate inside the chassis, aspect velocity of inlet/outlet and the position of outlet has an effect on CPU cooling.

Jeffrey P. Koplow [14] introduced new approaches to air-cooled heat exchangers without using the conventional air-cooled heat exchanger. This first prototype device was designed for an electronics cooling application. For heat exchanger approach Staats and Barisson [15] present an air cooled heat sink using integrated centrifugal fans in which fan blades are placed in close proximity to the heated surface where the air only entered into the top axial inlet and heated air is pumped radially outward. In this research they experimentally studied the fan curves, power consumption of planner and the heat transfer in this integrated fan system. Chao et al. [16] numerically investigate the thermal design of rack cooling system with pulsating heat pipe in data center and compare with experimental. In order to simplify the theoretical model turbulent flow is considered into the rack and molecular viscosity is neglected. In this research, turbulent flow is also considered and viscosity is neglected for forced convection air cooling method.

Computational fluid Dynamics (CFD) is a technique for solving governing equations of fluid dynamics and heat transfer numerically with the help of computers. It is also known as flow simulation or computer simulation. Flow pattern and heat transfer characteristics can easily be predicted using this technique. Therefore, it is very popular and widely used. Yabo et al. [17] predicted different positions of outlet numerically. Prajapati [18] studied heat transfer and fluid flow behavior numerically in rectangular parallel micro channel heat sinks by varying fin height. Yunke Zhong et al. [19] carried out simulated results to study the flow and heat transfer characteristics of mist in a wire rod bundle. They discussed the turbulent flow behavior and the heat transfer performance of post-CHF (critical heat flux) mist flow in the rod bundle.

During its operation the CPU dissipates heat that makes the air warmer inside the chassis. Eventually, warmer air needs to be replaced with cooler air for saving the CPU from overheating. In this cooling cycle the aspect ratio of the inlet and the outlet plays an important role. Since the air flows in two directions inside the fin channel, this study considers a plate fin heat sink. Furthermore, depending on the heat sink fin orientation, the outlet position is tested and discussed to analyze the cooling effect. A velocity ratio between the inlet air flow and the outlet airflow is also considered as the outlet airflow also come out by the force. Since the present study involves a variety of geometry modifications, this study takes the advantages of computational approach. It is obvious that the computational approach with the help of technologies can deal with a myriad amount of cases and data with comparatively less efforts. The flow and the temperature distributions are predicted using ANSYS CFX [20] for different geometry and the relevant boundary conditions. The numerical methodology is verified satisfactorily after applying the methodology to resimulate some published cases. 


\section{Description of the Model}

Computational domain in the present work is a heat sink along with a normal size of CPU chassis. The chassis has $395 \mathrm{~mm}$ length, $180 \mathrm{~mm}$ width and $340 \mathrm{~mm}$ height. It has six sidewalls mentioned in Figure 1 where the inner sidewall is laid on the $x y$ plan. It has inlet on the outer sidewall, outlet on the back sidewall and $85 \mathrm{~cm}^{2}$ opening area on the front sidewall. Inlet is located at the opposite of the heat sink as it can blow air directly toward the heat sink, outlet blows air outside of the chassis and opening balances the air pressure gradient inside the chassis. A rectangular fin heat sink is placed on the top of the processor which is located on the inner sidewall. The dimension of the heat sink is $85 \mathrm{~mm} \times 85 \mathrm{~mm} \times 25$ $\mathrm{mm}$ with $1 \mathrm{~mm}$ width fin. Fins are horizontally oriented. The model in the present work is drawn by software CATIA [21] shown in the following Figure 1.

\section{Numerical Method}

The following steps are followed to simulate the problem of the system numerically:

\subsection{Governing Equations, Boundary Conditions and Numerical Solution}

The instantaneous equation of mass, momentum and energy conservation can be written in the following form.

Conservation of mass

$$
\frac{\partial}{\partial x_{j}}\left(U_{j}\right)=0 ; j=1,2,3
$$

Conservation of momentum

$$
\rho U_{j} \frac{\partial}{x_{j}}\left(U_{j}\right)=\frac{\partial p}{\partial x_{i}}+\frac{\partial}{\partial x_{j}}\left[\left(\mu+\mu_{t}\right) \frac{\partial U_{i}}{\partial x_{j}}\right]+\rho_{0} g_{i} \beta\left(T-T_{0}\right) ; i=1,2,3 \& j=1,2,3
$$

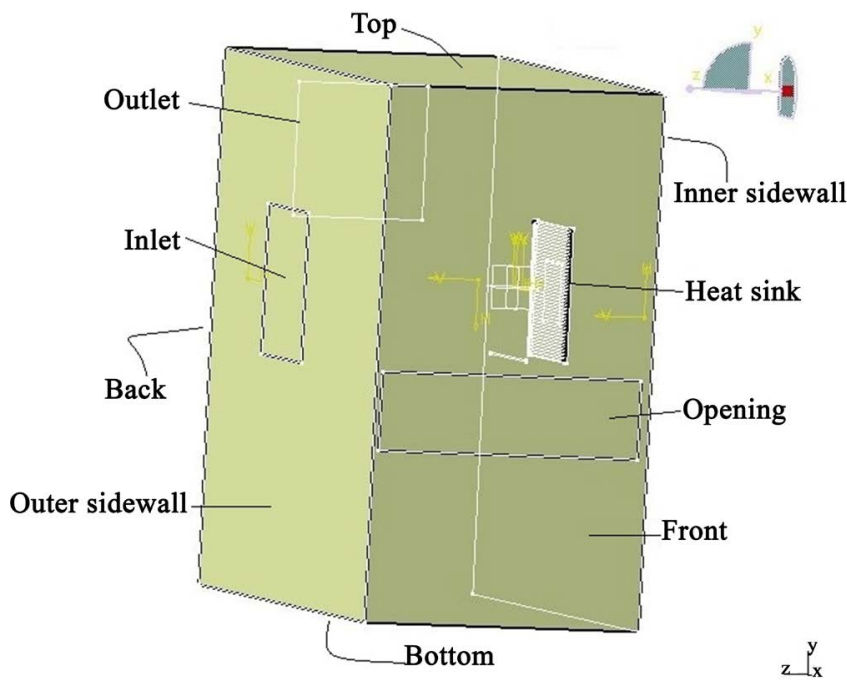

Figure 1. Computational geometry (CPU chassis). 
Conservation of energy

$$
U_{j} \frac{\partial}{\partial x_{j}}(T)=\frac{\partial}{\partial x_{j}}\left[\left(\frac{v}{P_{r}}+\frac{v_{t}}{\sigma_{t}}\right) \frac{\partial T}{\partial x_{j}}\right] ; j=1,2,3
$$

Equation of state

$$
p=\rho R T
$$

In these equations $U$ is the velocity vector. $p_{r}=\frac{\mu C_{p}}{k}$ is the prandtl number, $p$ is the air static pressure, $\mu$ is the air viscosity, $v$ is the kinematic viscosity, $k$ is the thermal conductivity, $g_{i}$ is the gravitational acceleration, $R$ is the ideal gas constant, $\rho$ is the density of air at temperature $T$ and $\rho_{0}$ is the density of air at temperature $T_{0}$. The Bousinessq approximation $\rho_{0} g_{i} \beta\left(T-T_{0}\right)$ is used in the momentum equation to model the buoyancy force. The transport equation for $k-\varepsilon$ turbulence model is given below,

The k equation, $\rho \frac{\partial}{\partial x_{j}}\left(U_{j} k\right)=\frac{\partial}{\partial x_{j}}\left[\left(\mu+\frac{\mu_{t}}{\sigma_{k}}\right) \frac{\partial k}{\partial x_{j}}\right]+P_{k}-\rho \varepsilon$

The $\varepsilon$ equation, $\rho \frac{\partial}{\partial x_{j}}\left(U_{j} \varepsilon\right)=\frac{\partial}{\partial x_{j}}\left[\left(\mu+\frac{\mu_{t}}{\sigma_{\varepsilon}}\right) \frac{\partial \varepsilon}{\partial x_{j}}\right]+\frac{\varepsilon}{k}\left(C_{\varepsilon 1} P_{k}-C_{\varepsilon 2} \rho \varepsilon\right)$

where the turbulence viscosity $\mu_{t}$ is linked to the turbulence kinetic energy $(k)$ and dissipation $(\varepsilon)$ via the relation

$$
\mu_{t}=C_{\mu} \rho \frac{k^{2}}{\varepsilon}
$$

where $C_{\mu}$ is constant.

Assuming steady state three dimensional flow inside the chassis all of the governing equations need to be solve and in the solid domain only energy equation needs to be solved. The property of air at $25^{\circ} \mathrm{C}$ and $1 \mathrm{~atm}$ are considered inside the chassis. All of the flow regimes are subsonic and the airflow is assumed buoyant. Heat transfer is initiated due to thermal energy. Other boundary conditions are:

1) Inlet: $u=0 \mathrm{~m} \cdot \mathrm{s}^{-1}, v=0 \mathrm{~m} \cdot \mathrm{s}^{-1}, w=5 \mathrm{~m} \cdot \mathrm{s}^{-1}$,

2) Outlet: $u=8 \mathrm{~m} \cdot \mathrm{s}^{-1}, v=0, w=0$,

3) Opening: Opening pressure and direction with relative pressure 0 pa and opening temperature is set at $25^{\circ} \mathrm{C}$,

4) Heat flux: 64,711 $\mathrm{Wm}^{2}$

A CFD software, ANSYS CFX-Solver Manager is used to solve the governing equation at each mesh element of the computational domain. The high resolution scheme; a particular scheme provided in the ANSYS software is chosen. The convergent solution is achieved with the residual target $5.5 \times 10^{-4}$.

\subsection{Grid Distribution}

In the present work an unstructured mesh is generated in the fluid domain as well as solid domain by using ANSYS ICEM CFD 15.0. In the mesh generation 
strategy, mesh density at heat sink, inlet, outlet and opening is made denser than the rest of the computational domain. Primarily an unstructured tetrahedral mixed mesh is generated for global parameter of maximum element of $6.0 \mathrm{~mm}$ and density region of maximum element of $2.5 \mathrm{~mm}$. This combination gives the total of 3.1 million mesh elements. But to get a well converged and acceptable solution an optimum mesh topology is required. For that reason, several meshes are generated considering different global mesh parameters and density regions. From the simulated results it is found that $5.5 \mathrm{~mm}$ global mesh parameter and $2.29 \mathrm{~mm}$ density region gives 4.0 million mesh elements which are chosen as optimum. This optimum mesh topology is shown in Figure 2 and Figure 3.

\section{Validation of Methodology}

To validate the results, a pin fin heat sink is considered which is reported by Ozturk and Tari [22]. The heat sink is drawn according to the reported geometry and the simulation is done considering the same boundary conditions.

From Table 1, it is seen that the average temperature rises above ambient is reported $18.7^{\circ}$ where this temperature is found $20.9^{\circ}$ in our computations. The discrepancy in the temperature rise is $2.2^{\circ}$ due to lack of analogy in the geometry,

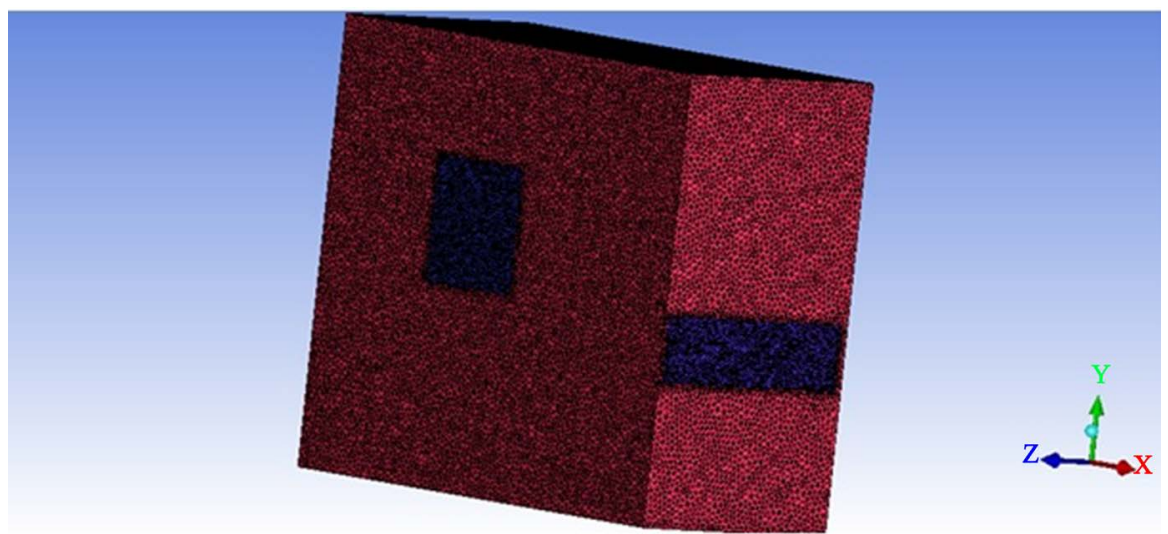

Figure 2. Final meshed geometry.

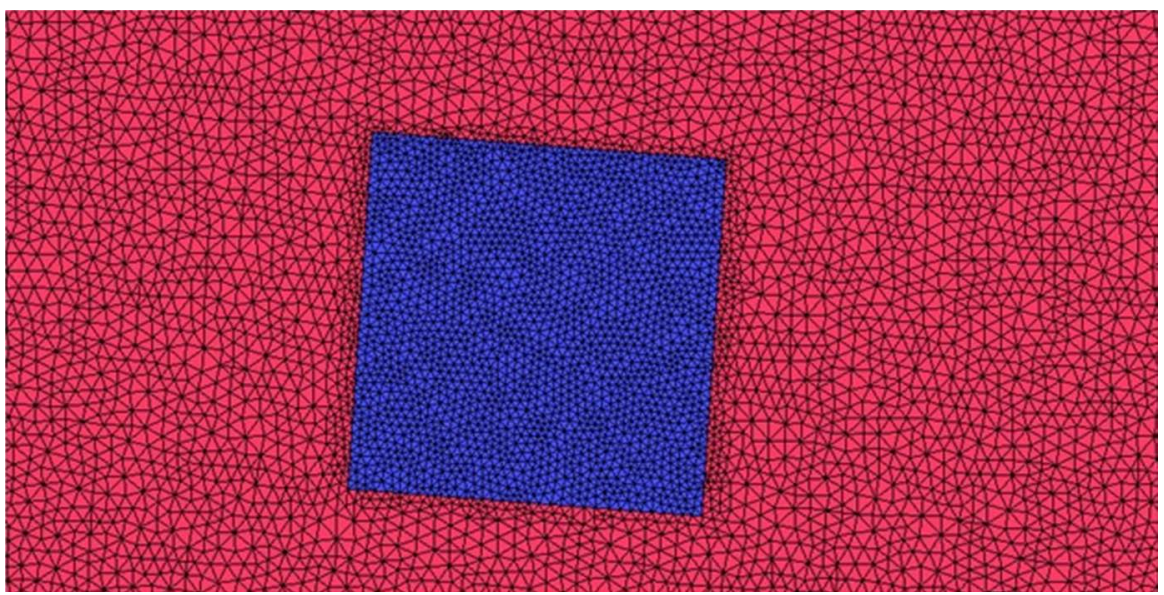

Figure 3. Comparison view between global mesh region and density mesh region. 
Table 1. Comparison of the temperature difference with [22] for $70 \mathrm{~W}$ heat source (CPU).

\begin{tabular}{ccc}
\hline & Alpha PAL8952 & Present Case \\
\hline$T_{\max }(\mathrm{K})$ & 328 & 324.5 \\
$T_{\min }(\mathrm{K})$ & 316 & 315.9 \\
$T_{\max }-T_{\min }(\mathrm{K})$ & 12 & 8.6 \\
Average rise above ambient, $\Delta T(\mathrm{~K})$ & 18.7 & 20.9 \\
Normalized non uniformity $\left(T_{\max }-T_{\min }\right) / \Delta T$ & 0.64 & 0.41 \\
\hline
\end{tabular}

flow conditions and boundaries between two cases. The temperature difference between $T_{\max }$ is $3.5^{\circ}$. The air velocity is not strong enough is the direct path along the fan hub and the heat sink. As a result, a hot spot is induced on the heat sink in that path. The larger maximum temperature in the heat sink [22] may be attributed to this fact. In this present simulation for validation, no fan is considered, that creates no hot spot. That's why our maximum temperature is reasonably lower than that of the reported results [22].

\section{Results and Discussion}

A steady-state conjugate heat transfer process is studied here numerically. Flow distribution and the effects of different boundary conditions are discussed here as follows:

\subsection{Effects of Outlet Position}

Position of outlet is very important for flow distribution inside the chassis [19]. In the present work, the outlet is located on the back sidewall of the chassis as mentioned previously. Eight different 3-D geometries are created for different positions of the outlet. Table 2 represents the exact positions of the outlet on the back sidewall with their orders. And the positions can be realized from Figure 4 .

With an optimum mesh topology for every case, simulations are done and all results are gathered to find out the best position of the outlet. Results are shown in tabular form in Table 3 as well as plotted graphically in Figure 5.

From Figure 5 it is realized that the position 2, 3 and 5 give better performance than the other positions. Comparing the position 2 and 3 it can be concluded that to get better thermal performance, the position of outlet need to take as corner as possible. This is because of the inlet air flow. For other positions of outlet, inlet air flow is disrupted by the outlet. Air flow moves toward the outlet without reaching the fin channel properly. There for convection rate is low for these positions. Although position 2 is little bit better than 3 but in real case, to set up outlet in that position can make difficulties, because, it has nuts, bolts or screws. For that reason, further improvement of the present work position 3 is chosen. But one should use the outlet as corner as possible in the similar case to get better performance. 
Table 2. Positions of outlet in details with their orders.

\begin{tabular}{cccc}
\hline $\begin{array}{c}\text { Order of } \\
\text { position }\end{array}$ & Exact position & $\begin{array}{c}\text { Order of } \\
\text { position }\end{array}$ & Exact position \\
\hline 1 & Middle of the wall & 5 & Along heat sink \\
2 & $10 \mathrm{~mm}$ from top and $5 \mathrm{~mm}$ from inner sidewall & 6 & Bottom half of the heat sink \\
3 (Chosen) & $20 \mathrm{~mm}$ from top and $5 \mathrm{~mm}$ from inner sidewall & 7 & Top half of heat sink \\
4 & $20 \mathrm{~mm}$ from top and $80 \mathrm{~mm}$ from inner sidewall & 8 & $\begin{array}{c}20 \text { mm from bottom and } \\
\text { middle of the wall }\end{array}$
\end{tabular}

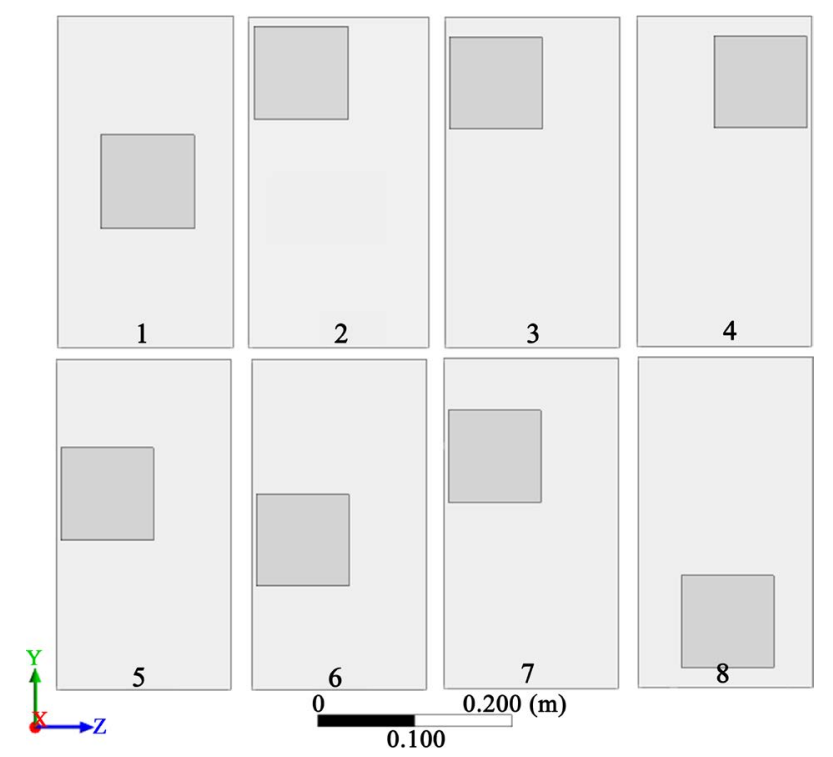

Figure 4. Different positions of outlet on the back sidewall of CPU chassis.

Table 3. Maximum CPU surface temperature for different positions of outlet.

\begin{tabular}{cccc}
\hline Order of outlet position & Temperature $\left({ }^{\circ} \mathrm{C}\right)$ & Order of outlet position & Temperature $\left({ }^{\circ} \mathrm{C}\right)$ \\
\hline 1 & 77.45 & 5 & 59.33 \\
2 & 59.38 & 6 & 62.39 \\
3 & 59.64 & 7 & 60.38 \\
4 & 62.10 & 8 & 64.53 \\
\hline
\end{tabular}

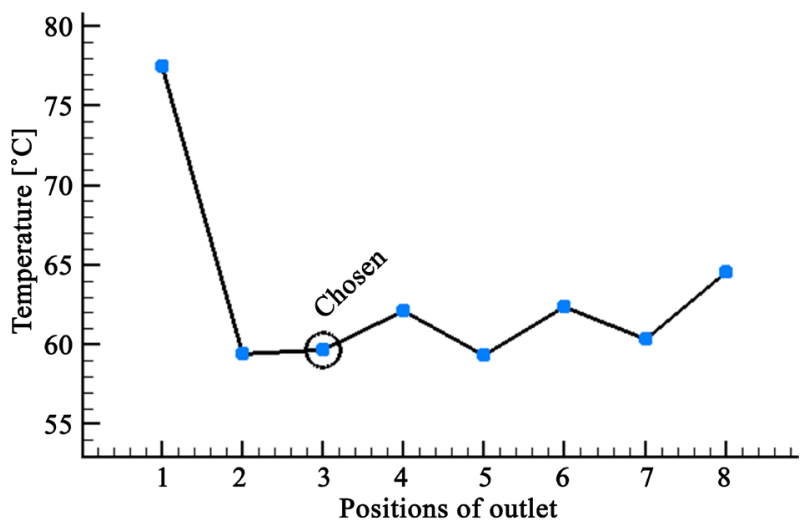

Figure 5. Maximum CPU surface temperature for different positions of outlet. 


\subsection{Effects of Dimension of Inlet and Outlet}

In the present work both inlet and outlet have the same dimension for the entire work and that is $95 \mathrm{~mm} \times 95 \mathrm{~mm}$ square. The larger the inlet/outlet the larger the mass flow rate and therefore larger convective heat transfer rate. But CPU chassis has complexity in real case. It has many wires and ports to connect peripheral devices. Also, chassis contains other components such as power supply, hard disk, motherboard, DVD drive etc. As a result, inlet and outlet can't be so large. Considering this phenomena five different dimensions of the inlet/outlet are created and simulated to predict the desired dimension. For all cases inlet/outlet is a square shaped and their position is $5 \mathrm{~mm}$ from inner sidewall and $20 \mathrm{~mm}$ from the top. The work history and simulated results are shown in Table 4 and Figure 6.

From Table 4 it is seen that in all cases, temperature varies from $59.31^{\circ} \mathrm{C}$ to $60.38^{\circ} \mathrm{C}$ that is acceptable. But $85 \mathrm{~mm} \times 85 \mathrm{~mm}$ outlet is better than any other dimensions. In the case of larger dimension air flow moves toward the surface parallel to the outlet without reaching to the fin channel. And for smaller dimension, mass flow rate is lower. In the present case, $85 \mathrm{~mm} \times 85 \mathrm{~mm}$ dimension of the inlet/outlet is comparatively suitable.

\subsection{Effects of Inlet-Outlet Velocity Ratio}

The inlet blows air inside the chassis and outlet blows air outside of the chassis. Thus the velocity ratio of inlet and outlet is very important for flow distribution inside the chassis, mostly around the heat sink and inside the fin channel of the heat sink. To optimize the velocity ratio, several simulations are done for the ratio of inlet-outlet from 1:1 to 1:2. In all cases, inlet has a fixed velocity $\left(5 \mathrm{~ms}^{-1}\right)$

Table 4. Maximum CPU surface temperature for different dimensions of inlet-outlet.

\begin{tabular}{cccc}
\hline $\begin{array}{c}\text { Dimension of } \\
\text { inlet-outlet }(\mathrm{mm})\end{array}$ & Temperature $\left({ }^{\circ} \mathrm{C}\right)$ & $\begin{array}{c}\text { Dimension of } \\
\text { inlet-outlet }(\mathrm{mm})\end{array}$ & Temperature $\left({ }^{\circ} \mathrm{C}\right)$ \\
\hline $65 \times 65$ & 60.98 & $95 \times 95$ & 59.64 \\
$75 \times 75$ & 59.90 & $105 \times 105$ & 59.37 \\
$85 \times 85$ & 59.31 & &
\end{tabular}

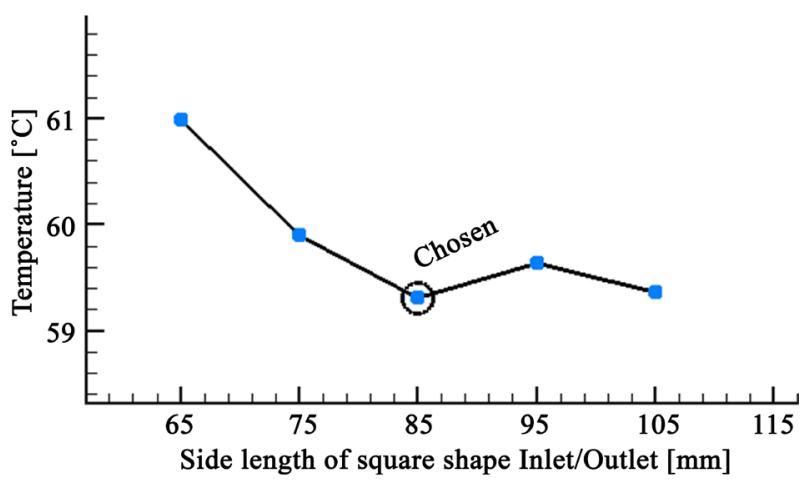

Figure 6. Maximum CPU surface temperature for inlet/outlet dimensions. 
but outlet velocity is varied from $5 \mathrm{~ms}^{-1}$ to $10 \mathrm{~ms}^{-1}$ in the interval of $2 \mathrm{~ms}^{-1}$. It is found that 1:1.6 ratio helped the heat sink for giving higher convective heat transfer rate. The work history and simulated results are summarized in Table 5 and Figure 7. It is observed from Figure 7 that for ratios 1:1.8 and 1:2, the maximum temperature of $\mathrm{CPU}$ surface is greater than the other ratios. In these cases, the outlet velocities are $9 \mathrm{~ms}^{-1}$ and $10 \mathrm{~ms}^{-1}$. For the larger outlet velocity, inlet air flow is disrupted by the outlet. The flow moves toward the outlet without reaching fin channel.

\subsection{The Flow and Heat Transfer Characteristics}

Numerical computations are carried out for a $91 \mathrm{~W}$ CPU (maximum load). Having all of the analysis together, a general case is set for this study. In this general case it is found that the horizontal fin orientation with 1:1.6 inlet-outlet velocity ratio the heat sink gives a better thermal performance when outlet is located at the top corner of the chassis, near to the inner sidewall. It is found that the avergae temperature of the fluid inside the chassis is calculated $26.7^{\circ} \mathrm{C}$, that is slightly above the room temperature. To visualize the flow field and heat transfer characteristics inside the chassis, three planes are created, parallel to the xy plane, namely plane 1, plane 2 and plane 3 ilustrated in Figure 8. Plane 1 passes through the contact region of the fin and the base plate of the heat sink, plane 2 is located at the center of the chassis and plane 3 is located near to the

Table 5. Maximum CPU surface temperature for inlet-outlet velocity ratio.

\begin{tabular}{cccc}
\hline \multicolumn{2}{c}{ Velocity $\left(\mathrm{ms}^{-1}\right)$} & Velocity ratio of inlet-outlet & Temperature $\left({ }^{\circ} \mathrm{C}\right)$ \\
\hline Inlet & Outlet & $1: 1$ & 63.84 \\
5 & 5 & $1: 1.2$ & 64.88 \\
5 & 6 & $1: 1.4$ & 61.50 \\
5 & 7 & $1: 1.6$ & 59.64 \\
5 & 8 & $1: 1.8$ & 72.40 \\
5 & 9 & $1: 2$ & 78.36 \\
\hline
\end{tabular}

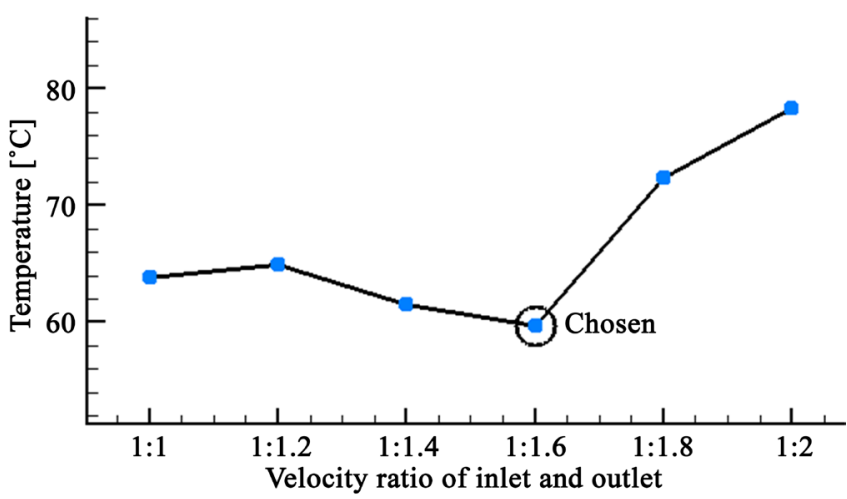

Figure 7. Maximum CPU surface temperature for velocity ratio of inlet and outlet. 
inlet. It is noted that the average temperature of plane 1, plane 2 and plane 3 are $34.43^{\circ} \mathrm{C}, 26.15^{\circ} \mathrm{C}$ and $26.45^{\circ} \mathrm{C}$, respectively. The overall temperature on plane 1 is relatively higher because, it passes through the heat sink.

The air flow path inside the chassis is very complicated. Air flow is entered into the chassis through the inlet and opening, but left through the outlet. Air flow path from the inlet and the outlet are shown in Figure 9 separately. Three

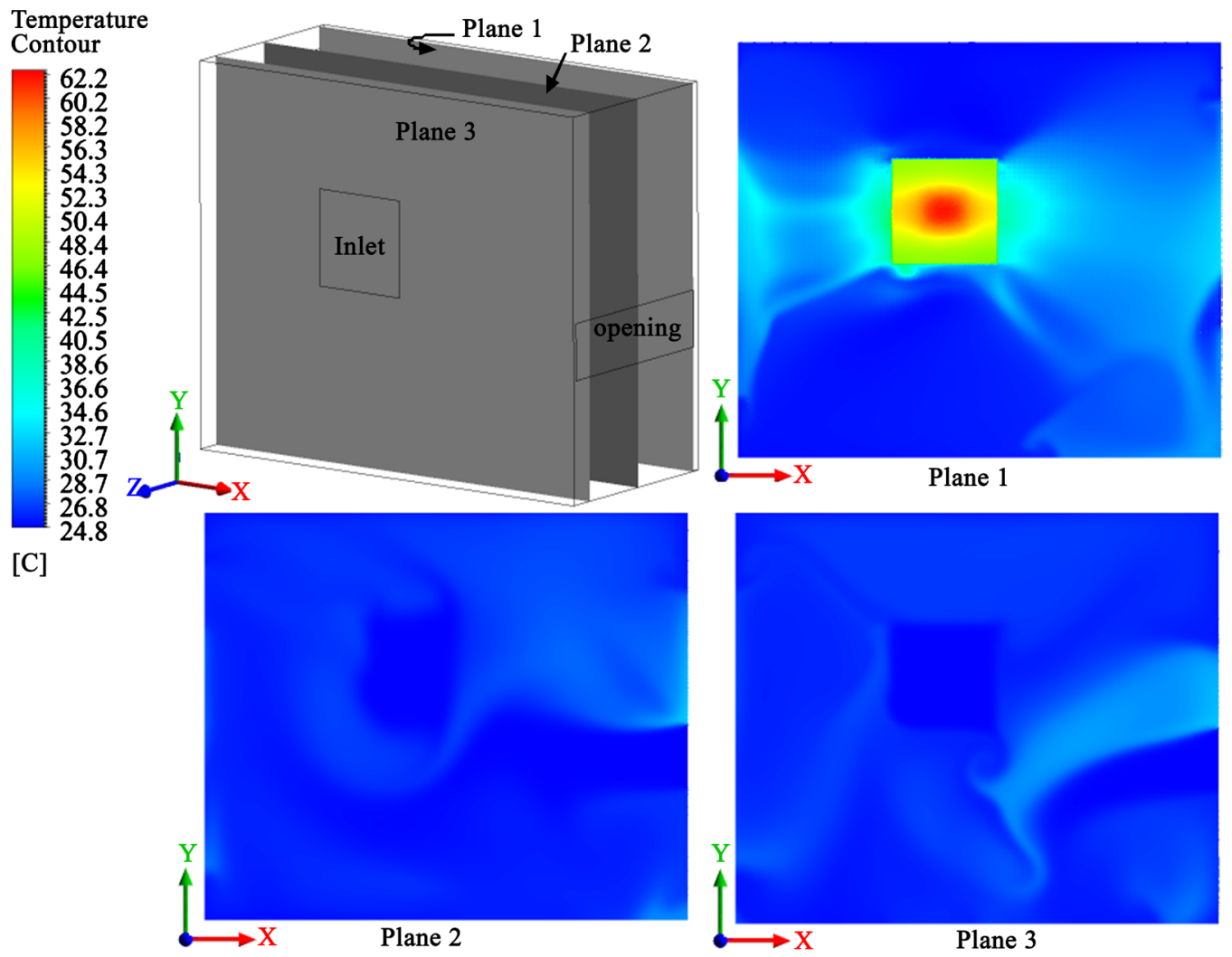

Figure 8. Temperature distribution inside the chassis.
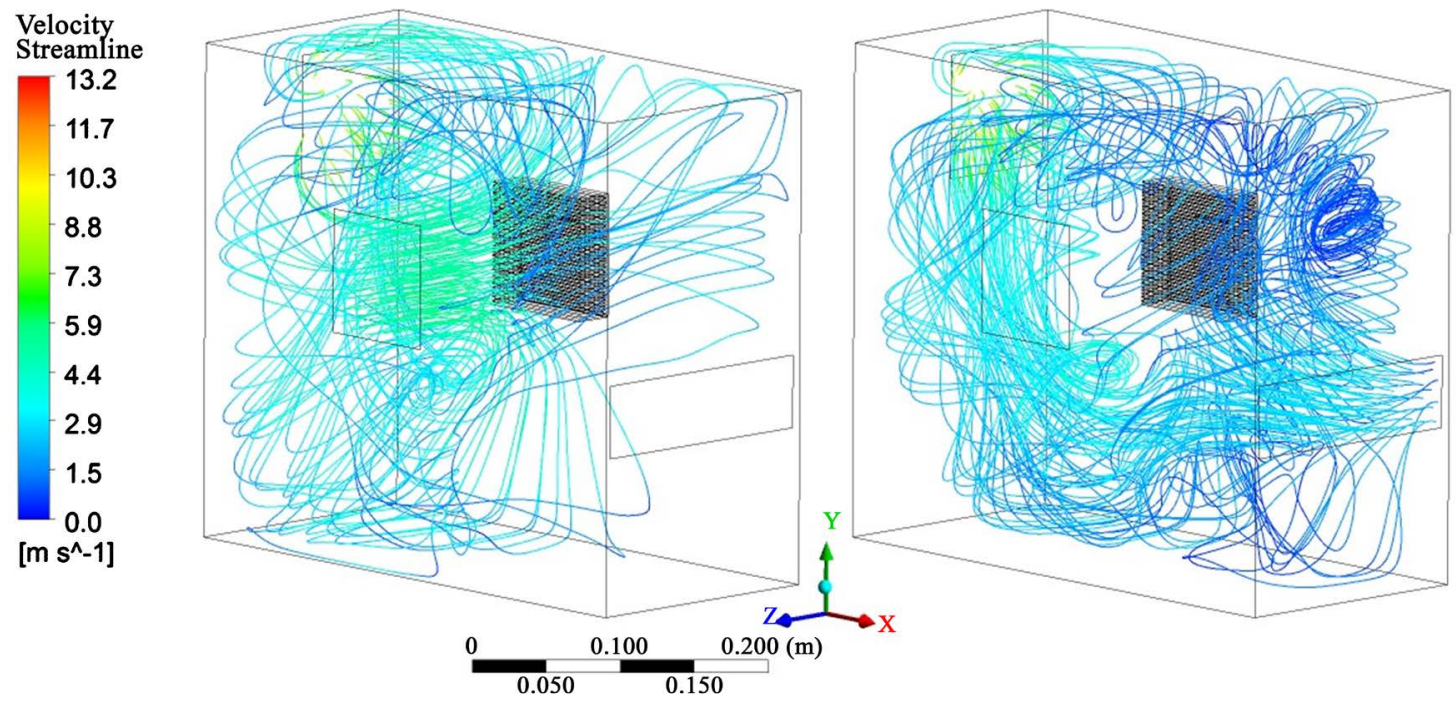

Figure 9. Streamline from inlet (left) and from opening (right). 
different planes as mentioned peviously also represent the streamline pattern for different positions shown in Figure 10. Inlet flow velocity is $5 \mathrm{~m}^{-1}$ and Reynolds Number is $4.2 \times 10^{3}$ that indicates that the flow is turbulent inside the chassis. The flow path on the plane 1 passing through the heat sink is less turbulent than that on other two planes and flow path on the plane 2 passing through the middle of the chassis is fully turbulent. Figure 9 and Figure 10 also show that how flow is entered into the chassis and left through the outlet.

The velocity vector expresses the direction of velocity over the domain. And the magnitude of the velocity can be realized from the scale. Higher and lower velocities for different positions of the chassis are observed from Figure 11. Higher velocity is found at the outlet, around fin or fin channel, inlet and opening. It is noted that the average velocity on plane 1, plane 2 and plane 3 are 2.63 $\mathrm{ms}^{-1}, 2.36 \mathrm{~ms}^{-1}$ and $1.91 \mathrm{~ms}^{-1}$, respectively.

\section{Conclusions}

A CPU Chassis is designed by the software CATIA containing a heat sink with horizontal fin orientation and then the domain is discretized using ICEM CFD. A two-equation based turbulence model is applied to capture the turbulence of the flow field. The governing equation at each grid is solved to determine a more effective geometry. The optimum velocity ratio of inlet/outlet, dimension of inlet/outlet and positions of outlet are predicted. The following conclusions can be
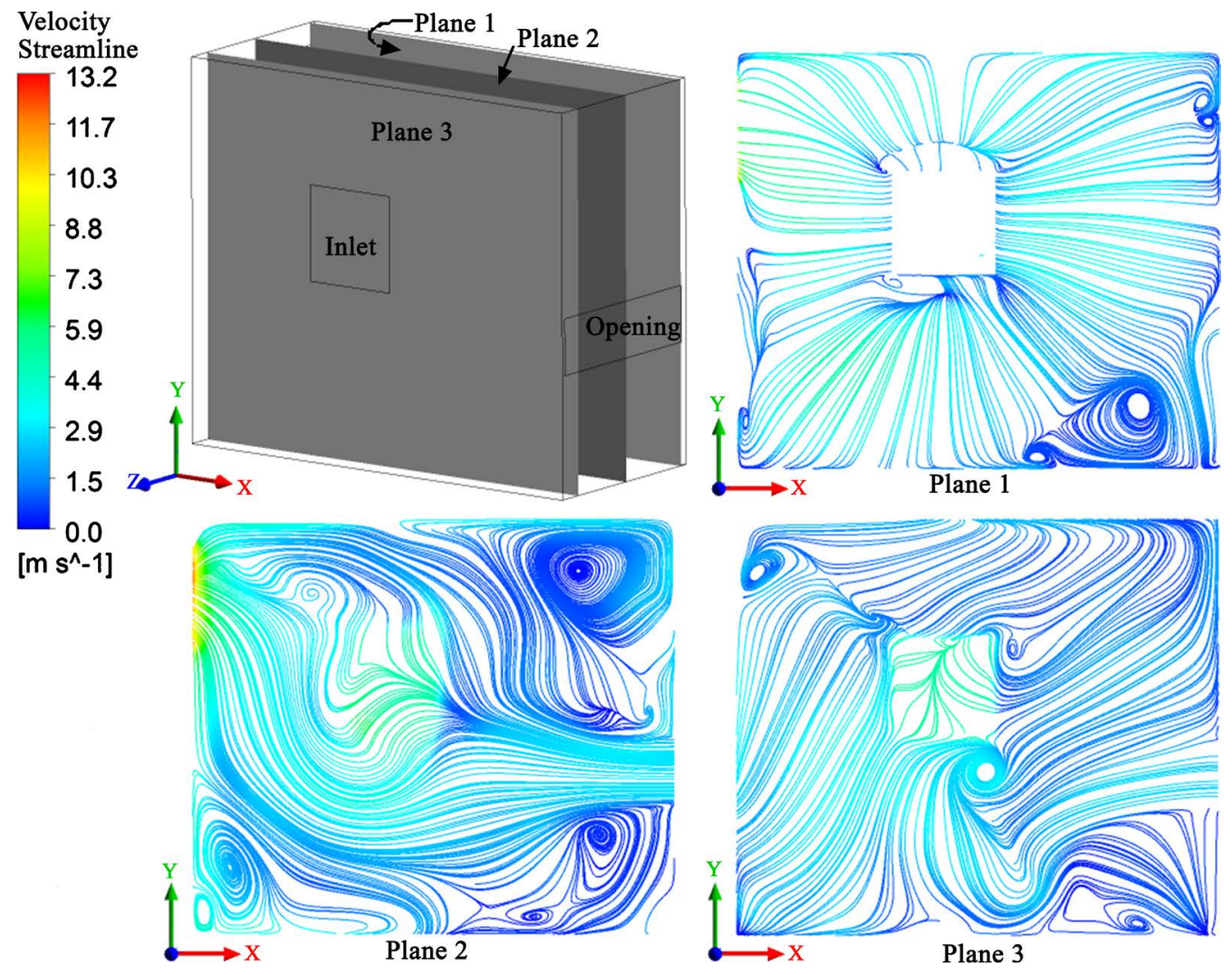

Figure 10. Streamline pattern inside the chassis. 


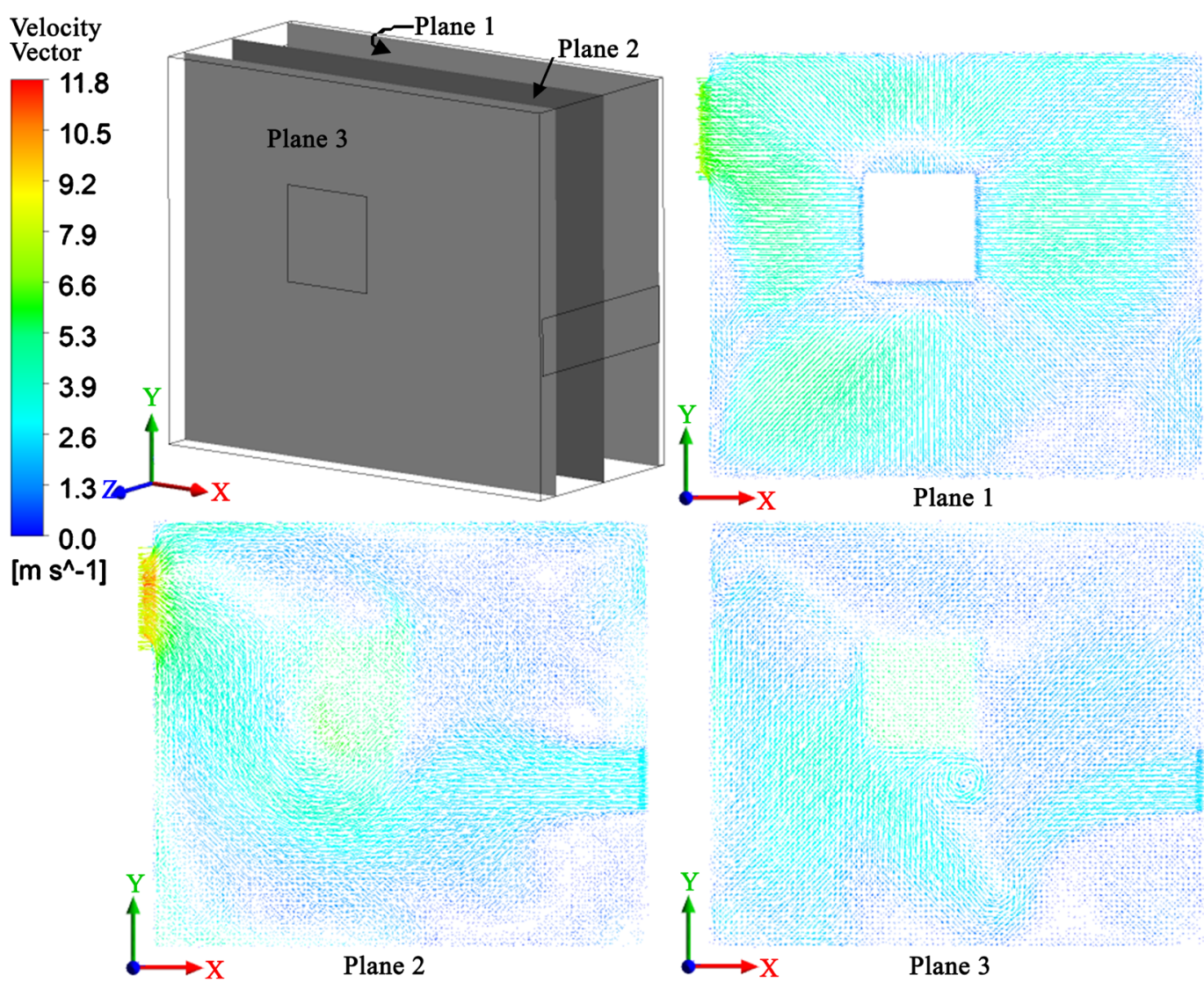

Figure 11. Velocity vector inside the chassis.

drawn from the results.

- The Reynolds number based on inflow velocity and geometry is $4.2 \times 10^{3}$, which indicated turbulent flow. The turbulent nuture of the flow is visible inside chassis.

- The studied model is found feasible to cool down the CPU.

- Heat sink has better thermal performance when outlet is positioned in the top corner of the chassis, near to the inner sidewall.

- A larger size of inlet/outlet is responsible for a higher mass flow rate, but in the present case, no significant change in maximum temperature is found for four-square shaped inlet/outlet from $95 \mathrm{~mm} \times 95 \mathrm{~mm}$, to $65 \mathrm{~mm} \times 65 \mathrm{~mm}$ in the interval of $10 \mathrm{~mm}$. Temperature variation of them is found $1.07^{\circ} \mathrm{C}$. Relatively better performance is gained from the dimension $85 \mathrm{~mm} \times 85 \mathrm{~mm}$.

- The proper thermal performance is achieved for inlet-outlet velocity ratio of $1: 1.6$.

For time limitation, this study considered the steady case only. However, an unsteady simulation is obviously a better choice to capture the real time phenomena. As unsteady simulation needs more computational time and more advanced computational facilities, this paper only examines steady-state cases. However, for more accurate results unsteady computations are necessary. A study on this topic may be extended considering the unsteadiness of the phenomena. 


\section{Conflicts of Interest}

The authors declare no conflicts of interest regarding the publication of this paper.

\section{References}

[1] Carr, J.D. (2014) An Examination of CPU Cooling Technologies. http://www.dsiventures.com

[2] Magadum, P.P. and Shamrao, G.M. (2015) Analysis \& Optimization of Processor Cooling Fins. International Journal of Engineering and Innovative Technology, 5, 90-94.

[3] Processor Core i7 7700k. http://ark.intel.com/products/97129/Intel-Core-i7-7700K-Processor-8M-C

[4] Tuckerman, D.B. and Pease, R.F.W. (1981) High Performance Heat Sinking for VLSI. IEEE Electron Device Letters, 2, 126-129. https://doi.org/10.1109/EDL.1981.25367

[5] Pastukhon, V.G. and Maydanik, Y.F. (2006) Low-Noise Cooling System for PC on the Base of Loop Heat Pipes. Institute of Thermal Physics, Ural Branch of the Russian Academy of Science, Ekaterinburg.

[6] Moon, S.H., Hwang, G., Yun, H.G., Choy, T.G. and Kang, Y. (2002) Improving Thermal Performance for Notebook PC Cooling. Microelectronic Reliability, 42, 135-140. https://doi.org/10.1016/S0026-2714(01)00226-8

[7] Kim, K.-S., Won, M.-H., Kim, J.-W. and Back, B.-J. (2003) Heat Pipe Cooling Technology for Desktop PC CPU. Applied Thermal Engineering, 23, 1137-1144. https://doi.org/10.1016/S1359-4311(03)00044-9

[8] Choi, J., Jeong, M., Yoo, J. and Seo, M. (2012) A New CPU Cooler Design Based on an Active Cooling Heat Sink Combined with Heat Pipes. Applied Thermal Engineering, 44, 50-56. https://doi.org/10.1016/j.applthermaleng.2012.03.027

[9] Satio, Y., Nguyen, T., et al. (2005) Revolution in Fan Heat Sink Cooling Technology to Extended and Maximize Air Cooling for Performance Processor in Laptop/Desktop/Several Application. IPACK 2005-7386, San Francisco, 17-22 July 2005, 431-437.

[10] Stafford, J., Walsh, E., Egan, V. and Grimes, R. (2010) Flat Plate Heat Transfer with Axial Fan Flows. International Journal of Heat and Mass Transfer, 53, 5829-5638. https://doi.org/10.1016/j.ijheatmasstransfer.2010.08.020

[11] Li, J. (2011) Computer Aided Modeling and Simulation of Cooling Fan. International Symposium on Information Engineering and Electronic Commerce (IEEC 2011), Bridgeport (USA), January 2011.

[12] Mousavi, H., Darazi, A.A., Farhadi, M. and Omidi, M. (2018) A Novel Heat Sink Design with Interrupted, Staggered and Capped Fins. International Journal of Thermal Science, 127, 312-320. https://doi.org/10.1016/j.ijthermalsci.2018.02.003

[13] Zeng, S., Kanargi, B. and Lee, P.S. (2018) Experimental and Numerical Investigation of a Mini Channel Forced Air Heat Sink Design by Topology Optimization. International Journal of Heat and Mass Transfer, 121, 663-679. https://doi.org/10.1016/j.ijheatmasstransfer.2018.01.039

[14] Koplow, J.P. (2010) A Fundamentally New Approaches to Air-Cooled Heat Exchangers. Sandia National Laboratories. https://doi.org/10.2172/984140

[15] Staats, W.L. and Barisson, J.G. (2015) Active Heat Transfer Enhancement in Air 
Cooled Heat Sink Using Integrated Centrifugal Fans. International Journal of Heat and Mass Transfer, 82, 189-205.

https://doi.org/10.1016/j.ijheatmasstransfer.2014.10.075

[16] Dang, C., Jia, L. and Lu, Q.Y. (2016) Investigation on Thermal Design of a Rack with the Pulsating Heat Pipe for Cooling CPUs. Applied Thermal Engineering, 110, 390-398. https://doi.org/10.1016/j.applthermaleng.2016.08.187

[17] Wang, Y.B., Zhu, K., Cui, Z. and Wei, J. (2019) Effects of Location of the Inlet and Outlet on Heat Transfer Performance in Pin Fin CPU Heat Sink. Applied Thermal Engineering, 151, 506-513.

[18] Prajapati, Y.K. (2019) Influence of Fin Height on Heat Transfer and Fluid Flow Characteristics of Rectangular Micro Channel Heat Sink. International Journal of Heat and Mass Transfer, 137, 1041-1052.

https://doi.org/10.1016/j.ijheatmasstransfer.2019.04.012

[19] Zhong, Y.K., Hu, L., Chen, D.Q., Liu, H.D., Yuan, D.W. and Liu, W.X. (2019) CFD Simulation on the Flow and Heat Transfer Characteristics of Mist Flow in Wire-Wrapped Rod Bundle. Nuclear Engineering and Design, 345, 62-73.

https://doi.org/10.1016/j.nucengdes.2019.02.003

[20] ANSYS CFX. http://www.ansys.com/Products/Fluids/ANSYS-CFX

[21] CATIA. http://www.3ds.com/products-services/catia

[22] Ozturk, E. and Tari, I. (2008) Forced Air Cooling of CPUs with Heat Sink: A Numerical Study. IEEE Transaction on Components and Packaging Technologies, 31, 650-660. https://doi.org/10.1109/TCAPT.2008.2001840 


\section{Nomenclature}

$\begin{array}{ll}K & \text { Thermal conductivity }\left[\mathrm{wm}^{-1} \cdot \mathrm{k}^{-1}\right] \\ A & \text { Cross sectional area }\left[\mathrm{cm}^{2}\right] \\ A_{s} & \text { Surface area }\left[\mathrm{cm}^{2}\right] \\ T & \text { Temperature }\left[{ }^{\circ} \mathrm{C}\right] \\ T_{s} & \text { Surface temperature }\left[{ }^{\circ} \mathrm{C}\right] \\ T_{0} & \text { Ambient fluid temperature }\left[{ }^{\circ} \mathrm{C}\right] \\ g & \text { Gravitational acceleration }\left[\mathrm{ms}^{-2}\right] \\ h & \text { Convective heat transfer coefficient }\left[\mathrm{wm}^{-2} \cdot \mathrm{k}^{-1}\right] \\ C_{p} & \text { Specific heat capacity }\left[\mathrm{Jg}^{-1} \cdot \mathrm{k}^{-1}\right] \\ k & \text { Turbulence kinetic energy per unit mass }\left[\mathrm{m}^{2} \cdot \mathrm{s}^{-1}\right] \\ \mathcal{E} & \text { Dissipation rate } \\ F_{1}, F_{2} & \text { Blending function } \\ u, v, W & X, y \text { and } z \text { components of velocity respectively }\left[\mathrm{ms}^{-1}\right] \\ X, y, Z & \text { Cartesian coordinate }[\mathrm{m}] \\ p & \text { Pressure }\left[\mathrm{kg} \cdot \mathrm{m}^{-1} \cdot \mathrm{s}^{-2}\right] \\ \dot{Q} & \text { Rate of conduction } \\ r^{\prime} & \text { Vector from upwind node to the point }\end{array}$

\section{Greek Symbols}

$\begin{array}{ll}\beta & \text { Thermal expansion coefficient }\left[\mathrm{k}^{-1}\right] \\ \mu & \text { Dynamic viscosity }\left[\mathrm{kg} \cdot \mathrm{m}^{-1} \cdot \mathrm{s}^{-1}\right] \\ \mu_{t} & \text { Turbulence viscosity }\left[\mathrm{kg} \cdot \mathrm{m}^{-1} \cdot \mathrm{s}^{-1}\right] \\ v & \text { Kinematic viscosity }\left[\mathrm{m}^{2} \cdot \mathrm{s}^{-1}\right] \\ \rho & \text { Density of the fluid }\left[\mathrm{kg} \cdot \mathrm{m}^{-3}\right] \\ \sigma_{T} & \text { Thermal diffusivity } \\ \varphi & \text { Flow property at the node } \\ \omega & \text { Turbulence frequency }\left[\mathrm{s}^{-1}\right]\end{array}$

